\section{An essential role of the JIP1 scaffold protein for JNK activation in adipose tissue}

\author{
Anja Jaeschke, ${ }^{1,2}$ Michael P. Czech, ${ }^{2}$ and \\ Roger J. Davis ${ }^{1,2,3}$ \\ ${ }^{1}$ Howard Hughes Medical Institute and ${ }^{2}$ Program in \\ Molecular Medicine, University of Massachusetts Medical \\ School, Worcester, Massachusetts 01605, USA
}

The c-Jun $\mathrm{NH}_{2}$-terminal kinase (JNK) is activated during obesity. One consequence of obesity is that JNK phosphorylates the adapter protein insulin receptor substrate 1 (IRS-1) on Ser 307 and inhibits signaling by the insulin receptor. JNK can therefore cause peripheral insulin resistance during obesity and may contribute to the development of type 2 diabetes. Here we report that the JNKinteracting protein 1 (JIP1) scaffold protein, which binds components of the JNK signaling module, is essential for JNK activation in the adipose tissue of obese mice. These data identify JIP1 as a novel molecular target for therapeutic intervention in the development of obesity.

Received April 29, 2004; revised version accepted June 14, 2004.

The prevalence of obesity and diabetes in the USA has increased dramatically in recent years, with almost $20 \%$ of adults classified as obese and $>7 \%$ having type 2 diabetes (Mokdad et al. 2001). The molecular mechanisms by which obesity leads to peripheral insulin resistance, impaired pancreatic $\beta$-cell function, and, eventually, diabetes are poorly understood. Recent studies, particularly those of mice deficient for key signal transduction molecules, are beginning to provide insight and potential models for studying the role of obesity in the development of type 2 diabetes. Such studies have implicated the c-Jun $\mathrm{NH}_{2}$-terminal kinase (JNK) signaling pathway in diabetes (Bennett et al. 2003; Manning and Davis 2003). JNK can inhibit insulin signaling by phosphorylating the adapter protein insulin receptor substrate 1 (IRS-1) on Ser 307 (Aguirre et al. 2000, 2002; Lee et al. 2003) and is strongly activated by inflammatory cytokines and free fatty acids-molecules that can contribute to the development of type 2 diabetes (Boden 1997; Uysal et al. 1997). Furthermore, Jnk $1^{-/-}$mice exhibit decreased adiposity, significantly improved insulin sensitivity, and enhanced insulin receptor signaling capacity (Hirosumi et al. 2002).

Recent studies have established an important role for scaffold proteins in the regulation of mitogen-activated protein (MAP) kinases, including JNK (Morrison and Davis 2003). Thus, the JNK-interacting protein 1 (JIP1)

[Keywords: JIP1; JNK; insulin; IRS-1; obesity; diabetes] ${ }^{3}$ Corresponding author.

E-MAIL Roger.Davis@Umassmed.edu; FAX (508) 856-3210. Article and publication are at http://www.genesdev.org/cgi/doi/10.1101/ gad.1216504. scaffold binds multiple components of the JNK signaling pathway, including mixed-lineage kinases, MAP kinase kinase 7, and JNK (Whitmarsh et al. 1998). JIP1 is highly expressed in the brain and in the $\beta$ cells of the islets of Langerhans (Dickens et al. 1997; Bonny et al. 1998). Studies of viable $\operatorname{Iip} 1^{-/-}$mice provided no evidence of a nonredundant role of JIP1 in $\beta$ cells, but JIP1-deficiency was found to suppress neurotoxicity and JNK activation in response to ischemia (Whitmarsh et al. 2001; Im et al. 2003). Genetic evidence for a role of JIP1 in responses to other stimuli or in other adult tissues remains to be established.

It has been demonstrated that JIP1 is a candidate type 2 diabetes gene in humans (Waeber et al. 2000). This observation suggests that JIP1 may be relevant to JNK regulation associated with insulin resistance and obesity. The purpose of this study was to test this hypothesis.

\section{Results and Discussion}

Jip1 mRNA is highly expressed in the brain (Fig. 1A). However, we also found Jip1 mRNA in white adipose tissue, and a low level of Jip1 mRNA was observed in muscle (Fig. 1A). No expression of Jip1 mRNA was detected in liver. The expression of JIP1 in adipose tissue was confirmed by immunoblot analysis (Fig. 1B).

To examine the role of JIP1 in adipose tissue, we investigated the effect of Jip1 gene disruption. We have previously reported that Jip $1^{-1-}$ mice are viable and fertile (Whitmarsh et al. 2001), and similar observations have been reported for an independently created line of Jip $1^{-1-}$ mice (Im et al. 2003). In contrast, a third independently created JIP1 mutant mouse line was found to have a preimplantation defect that caused early embryonic lethality (Thompson et al. 2001). It is most likely that the lethality observed in one of the three reported Jip1 gene disruption studies is related to the mouse strain background. The studies reported here were performed using viable Jip $1^{-/}$mice that were back-crossed onto the C57BL/6J strain.

No differences between the adipose tissue of wild-type and Jip $1^{-/-}$mice were detected by analysis of histology or gross morphology (data not shown). We therefore investigated whether differences in the adipose tissue response to hormonal challenge could be detected. Male mice were treated with insulin, and the epididymal fat pads were isolated. Cytoplasmic extracts were examined by immunoblot analysis. Increased tyrosine phosphorylation of the adapter protein IRS-1, a direct target of the insulin receptor tyrosine kinase, was observed in response to treatment of mice with insulin (Fig. 1C). This tyrosine phosphorylation of IRS-1 was markedly increased in JIP1-deficient mice compared with wild-type mice (Fig. 1C). Interestingly, the increased tyrosine phosphorylation correlated with reduced inhibitory phosphorylation of IRS-1 on the JNK site Ser 307 (Fig. 1C) and also correlated with increased insulin-induced phosphorylation of AKT (a downstream target of insulin signaling; Fig. 1D) in the adipose tissue of Jip $1^{-/-}$mice. Together, these data provide biochemical evidence for increased insulin sensitivity in the adipose tissue of Jip $1^{-/-}$ mice in vivo. 
A

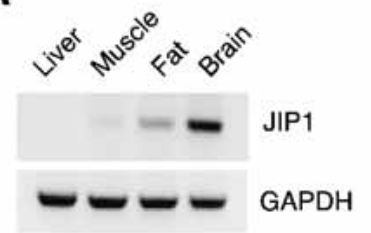

C

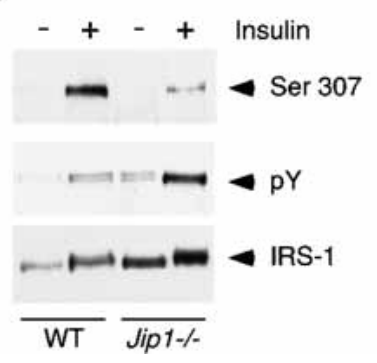

B

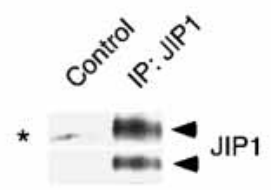

D

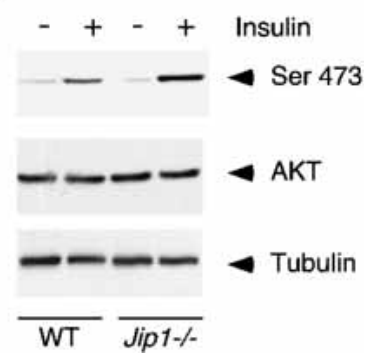

Figure 1. JIP1 is expressed in adipose tissue. (A) Jip1 and Gapdh mRNA in murine liver, muscle, fat, and brain was examined. $(B)$ JIP1 expression adipose tissue was examined by immunoblot analysis. (Asterisk) Nonspecific cross-reaction. $(C, D) J i p 1^{-/-}$and wild-type male mice were fasted overnight and treated with insulin $/ 1 \mathrm{U} / \mathrm{kg}$ body mass) by intraperitoneal injection. The epididymal fat pads were isolated after $30 \mathrm{~min}$ and were examined by immunoblot analysis to detect IRS-1, tyrosine phosphorylated (pY) IRS-1, and IRS-1 phosphorylated on Ser $307(C)$, and AKT, AKT phosphorylated on Ser 473, and Tubulin (D).

\section{JIP1-deficient mice are resistant to diet-induced obesity}

The observation that insulin signaling is altered in the adipose tissue of Jip $1^{-1-}$ mice indicates that JIP1-deficient mice should exhibit metabolic defects. To test this hypothesis, we investigated the effect of feeding the mice a high-fat/ high-caloric (HF) diet. After $16 \mathrm{wk}$, the Jip $1^{-/-}$mice gained $40 \%$ less weight than wild-type mice $(P<0.05)$. The difference in weight gain was associated with defects in the accumulation of adipose tissue in the Jip1 $1^{-/-}$mice. For example, the epididymal fat pad mass of wild-type and $\operatorname{Iip} 1^{-/-}$mice fed a standard diet was similar, but the Iip $1^{-/-}$mice exhibited markedly decreased fat mass compared with wild-type mice when fed the HF diet (Fig. 2A). The difference in fat mass was primarily accounted for by cell size. Sections of adipose tissue from HF-diet-fed Jip $1^{-/-}$mice indicated the presence of smaller adipocytes relative to wild-type mice (Fig. 2B). Decreased fat accumulation was also detected in the liver of $J i p 1^{-/-}$mice (Fig. 2C). The liver of the HF-diet-fed wild-type mice was paler in color and vacuolized because of an accumulation of fat droplets compared with Iip $1^{-/-}$mice. The decreased adiposity of Jip $1^{-/-}$mice may be caused by altered lipid metabolism, food intake, or core body temperature. However, no
A

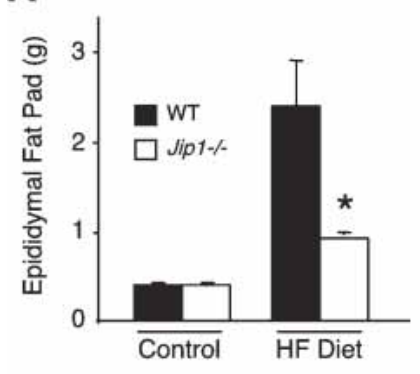

B WT
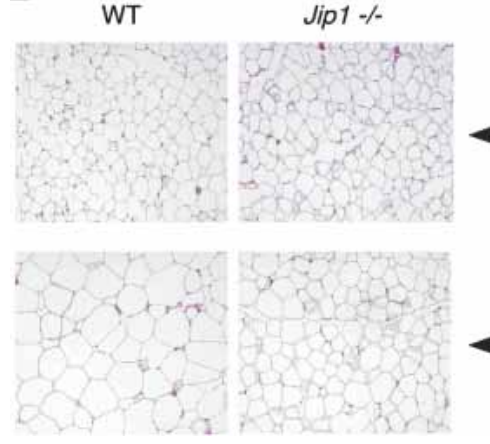

D
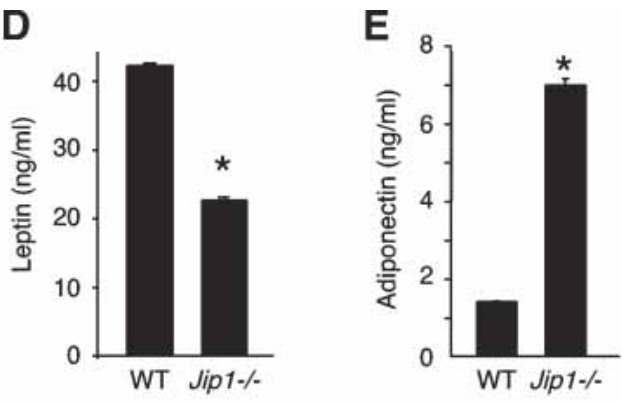

C
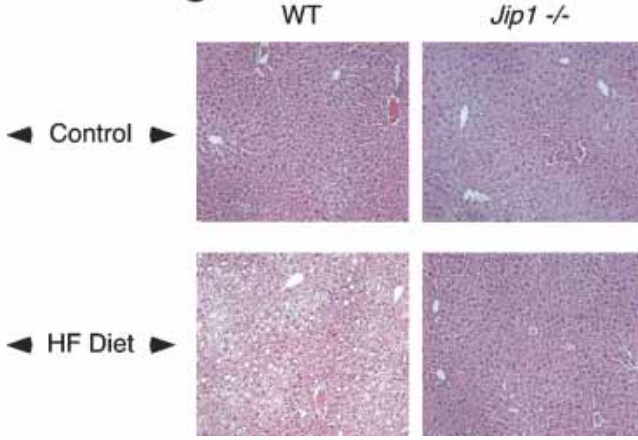

Figure 2. Reduced adiposity in Jip1 $1^{-/-}$mice. (A) Epididymal fat pad mass of Jip $1^{-/-}$and wild-type male mice fed a standard diet (Control) or an HF diet for $16 \mathrm{wk}$ (mean \pm S.E.M.; $n=10$ in each group). $(B, C)$ Representative histological sections of epididymal fat pads $(B)$ and liver $(C)$ stained with hematoxylin and eosin from wild-type and Jip1 $1^{-/-}$mice fed a standard diet (Control) or an HF diet are shown. (D) Plasma leptin concentration of Jip $1^{-/-}$ and wild-type male mice maintained on an HF diet for $16 \mathrm{wk}$ (mean \pm S.E.M.; $n=10$ in each group). (E) Plasma adiponectin concentration of Jip $1^{-/-}$and wild-type male mice maintained on an HF diet for $16 \mathrm{wk}$ (mean \pm S.E.M.; $n=10$ in each group). (Asterisk) Statistical significance $(P<0.05$ in $A ; P<0.01$ in $D, E)$ in a two-tailed Student's $t$-test comparing Jip $1^{-/-}$ mice with wild-type controls. 
fed an HF diet. However, the kinetics and severity of the hyperinsulinemia were reduced in $\operatorname{Iip1^{-/-}}$ mice (Fig. 3A). The increased plasma insulin in the HF-diet-fed mice was associated with an increase in the size of the islets in both wild-type and Iip $1^{-/-}$mice. However, consistent with the reduced severity of the hyperinsulinemia, the mean size of islets from HF-diet-fed Jip $1^{-/-}$mice was

A

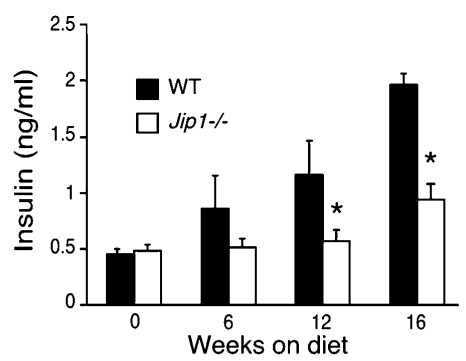

B

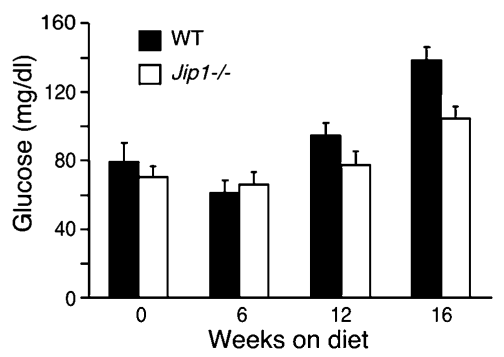

C

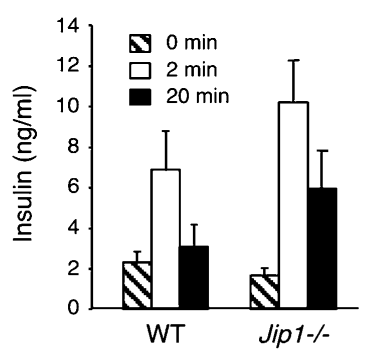

\section{D}

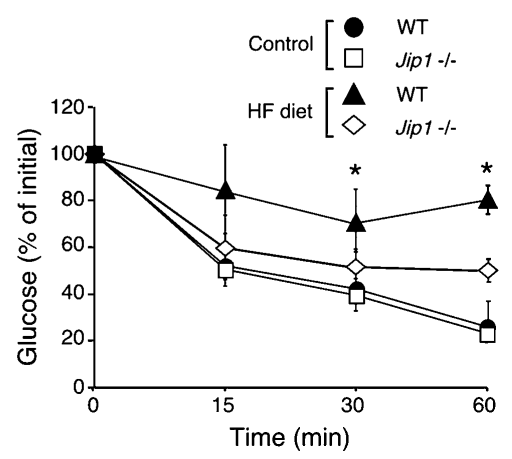

Figure 3. Metabolic effects of JIP1-deficiency. (A) Fasting plasma insulin concentration in $\mathrm{Iip}^{-/-}$and wild-type male mice maintained on an HF diet for 16 wk (mean \pm S.E.M.; $n=10$ in each group). (Asterisk) Statistical significance $(P<0.05)$ in a two-tailed Student's $t$-test comparing $J i p 1^{-1-}$ with wild-type mice. $(B)$ Fasting blood glucose concentrations in Jip1 $1^{-/-}$and wild-type male mice maintained on an HF diet for $16 \mathrm{wk}$ (mean \pm S.E.M; $n=10$ in each group). (C) Plasma insulin levels after a glucose load $(2 \mathrm{~g} / \mathrm{kg}$ body mass $)$ in mice fed on a high-fat diet (mean \pm S.E.M.; $n=10$ in each group). (D) Insulin-tolerance test in $\mathrm{Iip1}^{-/-}$and wild-type male mice maintained on a standard diet (lean) and on an HF diet (obese) for $16 \mathrm{wk}$ (mean \pm S.E.M.; $n=10$ in each group).
$30 \%$ less than wild-type mice (data not shown). Histological analysis did not detect obvious signs of $\beta$-cell degranulation in pancreas sections stained for insulin (data not shown). The HF-diet-fed wild-type and Jip1 $1^{-/-}$ mice showed a similar amount of acute insulin secretion following a glucose challenge (Fig. 3C), and these mice developed mild fasting hyperglycemia (Fig. 3B). Glucosetolerance tests of lean wild-type and Jip $1^{-/-}$mice performed by intraperitoneal injection of glucose demonstrated a similar rate of blood glucose clearance (data not shown). In contrast, HF-diet-fed wild-type mice were severely glucose intolerant and cleared blood glucose at a slower rate than HF-diet-fed Jip1 ${ }^{-/-}$mice (data not shown). We performed insulin-tolerance tests to examine the effect of insulin on blood glucose concentrations. Intraperitoneal injection of insulin caused reduced blood glucose concentrations in both wild-type and Iip1-1mice when fed a standard diet (Fig. 3D). As expected, HF-diet-fed wild-type mice showed marked insulin resistance in this assay. However, the HF-diet-fed Iip1 ${ }^{-1-}$ mice showed increased insulin sensitivity compared with wild-type mice, as indicated by the increased rate of glucose clearing on insulin challenge (Fig. 3D). Together, these data demonstrate that JIP1 deficiency protected mice against the development of obesity and insulin resistance.

\section{IIP1 is required for obesity-induced JNK activation}

To investigate the role of JIP1 in obesity-induced insulin resistance, we examined JNK phosphorylation by immunoblot analysis and JNK activity using an in vitro kinase assay. Obesity caused increased JNK activation in the fat, muscle, and liver of wild-type mice (Fig. 4). Similarly, the HF diet caused increased JNK activation in the liver of Jip $1^{-/-}$mice, but no JNK activation in fat or muscle was detected (Fig. 4). The selective effect of JIP1 deficiency to attenuate JNK activation in fat and muscle, but not liver, correlates with the pattern of JIP1 expression in wild-type mice (Fig. 1A), indicating that JIP1 is essential for obesity-induced activation of JNK in fat and muscle. The mechanism of obesity-induced JNK activation in the liver of $\mathrm{Jip}^{-/-}$mice is unclear, but it is possible that a different member of the JIP group of scaffold proteins is required for hepatic JNK activation (Morrison and Davis 2003). Thus, the major JIP isoforms expressed in adipose tissue and liver are JIP1 and JIP4, respectively.

IIP1 is required for obesity-induced phosphorylation of IRS-1 on Ser 307

What molecular mechanisms might contribute to the protection against obesity and improved insulin sensitivity in Jip1 $1^{-1-}$ mice? JNK can mediate an inhibitory feedback on insulin signaling by phosphorylation of IRS-1 on Ser 307 (Aguirre et al. 2000, 2002; Lee et al. 2003). Indeed, IRS-1 phosphorylation on Ser 307 was significantly increased in the fat, muscle, and liver of wildtype mice fed an HF diet (Fig. 5). However, increased Ser 307 phosphorylation was only detected in the liver of Jip $^{-1-}$ mice and was not observed in fat or muscle. These changes in IRS-1 phosphorylation on Ser 307 (Fig. 5) correlate with the level of JNK activation (Fig. 4) and JIP1 expression (Fig. 1A) in these tissues. 

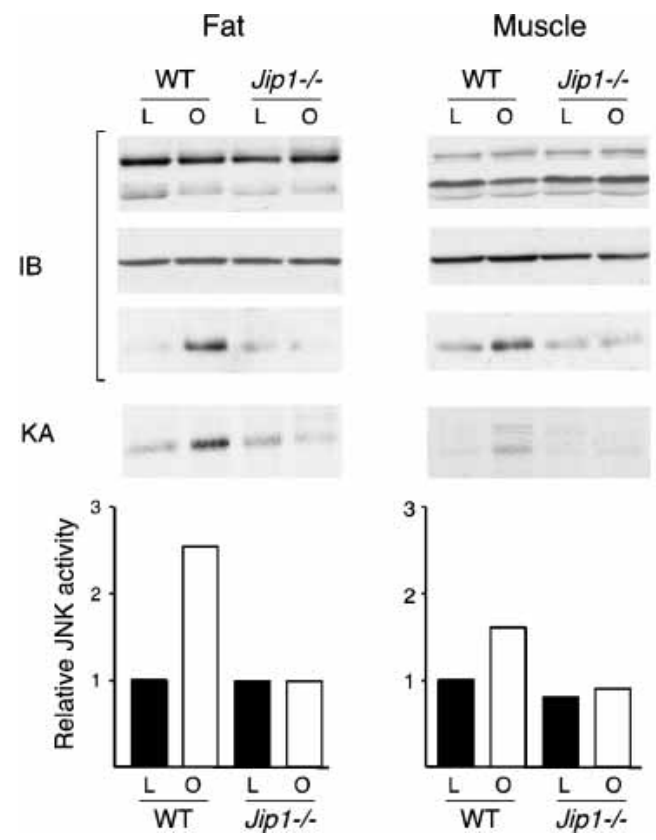
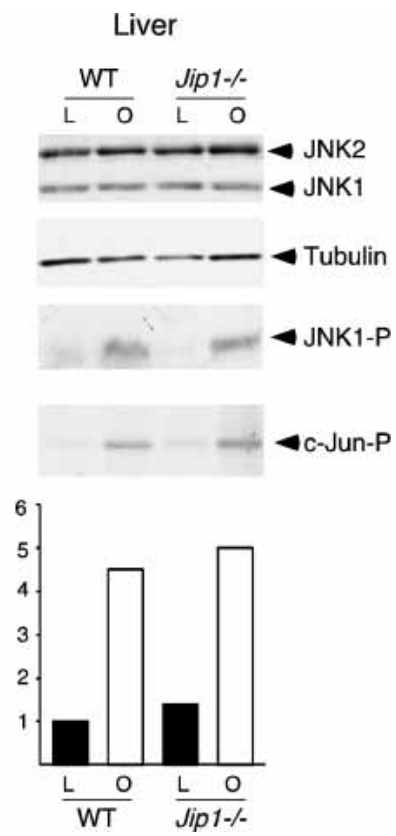

Figure 4. JIP1 is essential for obesity-induced JNK activation in adipose tissue. Extracts were prepared from the fat, muscle and liver of Jip1 $1^{-1-}$ and wild-type male mice maintained on a standard diet ([L] lean) and on an HF diet ([O] obese) for 16 wk. The expression of Tubulin, JNK, and phospho-JNK was examined by immunoblot analysis. JNK activity was measured in a kinase assay (KA) using c-Jun as the substrate and was quantitated by PhosphorImager analysis.

\section{IIP1 is essential for obesity-induced JNK activation in adipose tissue}

The results of this study demonstrate that the JIP1 scaffold protein is essential for JNK activation caused by obesity in adipose tissue and muscle, but not in liver. The defect in JNK activation in fat results in decreased inhibitory phosphorylation of IRS-1 on Ser 307 and consequently increased insulin sensitivity. The observation that JNK is activated in the liver of Jip1 ${ }^{-1-}$ mice demonstrates that the reduced JNK activation in fat and muscle is not a result of reduced obesity.

The absence of a defect in JNK activation in the liver of Jip $1^{-/-}$mice may account for the incomplete protection against insulin resistance observed in insulin-tolerance tests (Fig. 3D) because the liver plays a major role in postprandial glucose homeostasis and much of the decrease in blood glucose following insulin administration is caused by suppression of hepatic gluconeogenesis rather than an increase in muscle and adipose tissue glucose uptake (Michael et al. 2000; Mauvais-Jarvis et al. 2002). Nevertheless, our data demonstrate that JIP1 is essential for JNK regulation by obesity in fat and muscle (Fig. 4) and that Jip1 $1^{-1-}$ mice are protected against obesity (Fig. 2A).

It is likely that the adipose tissue defects of Jip $1^{-/-}$ mice contribute to the metabolic phenotype of these animals. However, metabolic phenotypes usually involve complex interactions between multiple tissues. It is therefore likely that some of the metabolic phenotype of the Jip $1^{-/-}$mice is accounted for by altered function of other tissues, including the hypothalamus and pancreatic $\beta$ cells. Nevertheless, previous studies have failed to identify central nervous system or $\beta$-cell defects in nonstressed Jip $1^{-/-}$mice, possibly as a result of complemen- tation by the related gene Jip2 (Whitmarsh et al. 2001). Significantly, Jip2 is selectively expressed in a limited number of tissues, including neurons and $\beta$ cells, whereas Jip1 is more broadly expressed in multiple tissues (Dickens et al. 1997; Yasuda et al. 1999). An important goal for further studies will therefore be the characterization of $J i p 2^{-/-}$mice and compound mutant Jip1 $1^{-/-}$Jip $2^{-/-}$mice.

Previous studies have demonstrated that the JIP1 scaffold protein is required for sustained JNK activation in neurons caused by ischemia but is not required for JNK activation caused by other stimuli (Whitmarsh et al. 2001; Im et al. 2003). Here we demonstrate that JIP1 is also essential for obesity-induced JNK activation in fat and muscle. This finding provides a new example of a MAP kinase signaling module that is regulated by a scaffold protein in vivo. JIP1-dependent JNK activation in fat contributes to the regulation of insulin sensitivity and adipose tissue mass. Drugs that inhibit JNK may be useful for the treatment of obesity and diabetes, but this approach may be limited by potential toxicity (Bennett et al. 2003; Manning and Davis 2003). The identification of an essential role for the JIP1 scaffold protein is therefore important because JIP1 represents a possible target for the design of therapeutic interventions in obesity. Inhibition of JIP1dependent JNK activation is likely to provide greater therapeutic specificity than a general inhibitor of JNK activity.

In summary, we provide evidence for a role of the JIP1 scaffold protein in the regulation of adipose mass and JNK activation associated with obesity and insulin resistance.

\section{Materials and methods}

Mice

Jip1 $1^{-/-}$mice (Whitmarsh et al. 2001) were back-crossed 10 generations to the C57Bl/6J strain (Jackson Laboratories) and were housed in a facility accredited by the American Association for Laboratory Animal Care (AALAC). The animal studies were approved by the Institutional Animal Care and Use Committee (IACUC) of the University of Massachusetts. Male mice (7 wk old) were fed an HF diet ad libitum (Diet F3282; BioServ) or a standard diet for $16 \mathrm{wk}$. Their body mass was recorded weekly. Blood samples were collected from the tail vein after an overnight fast or

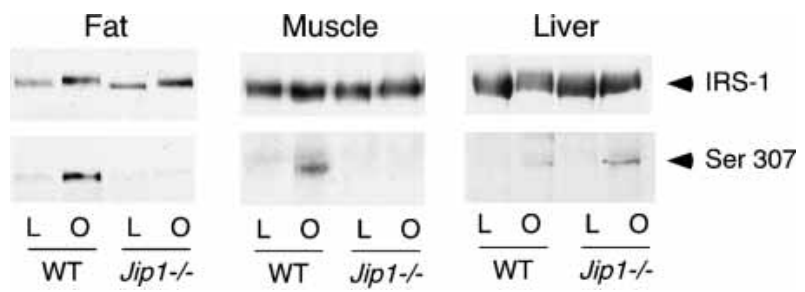

Figure 5. JIP1-deficiency prevents inhibitory phosphorylation of IRS-1 on Ser 307. IRS-1 expression and phosphorylation on Ser 307 in white adipose tissue, liver, and muscle of $\operatorname{Iip}^{-/-}$and wild-type male mice maintained on a standard diet ([L] lean) and on an HF diet ([O] obese) for $16 \mathrm{wk}$ was examined by immunoblot analysis. 
from the retro-orbital sinus after 6,12 , and $16 \mathrm{wk}$ on the diet. Blood glucose concentrations were measured by using a Dex-Glucometer (Bayer), and plasma insulin was measured by ELISA kit for rat insulin (Crystal Chem). Insulin-tolerance tests were performed on mice fed ad libitum by intraperitoneal administration of insulin $(0.75 \mathrm{U} / \mathrm{kg}$ body weight) and measurement of blood glucose at $0,15,30$, and 60 min after injection. Plasma leptin was determined using a mouse leptin ELISA kit (Crystal Chem). Adiponectin was measured with a mouse/rat adiponectin ELISA kit (B-Bridge International). Histology was performed using adipose tissue, pancreas, and liver fixed in $10 \%$ formalin for $24 \mathrm{~h}$, dehydrated, and embedded in paraffin. Sections $(5 \mu \mathrm{m})$ were cut and stained with hematoxylin and eosin.

\section{Biochemical assays}

Tissues were removed and rapidly frozen in liquid nitrogen. RNA was prepared (RNeasy kit; Qiagen) and used as the template for PCR with a Titan one tube RT-PCR kit (Roche) using amplimers for JIP1 (CTC GAGCCGCACATCTGCC and AAGCACAGTTGGCAGGACCG) and GAPDH (ACCACAGTCCATGCCATCAC and TCCACCACCCTGTT GCTGTA). JIP1 expression in adipose tissue was examined by immunoprecipitation with a monoclonal JIP1 antibody (Transduction Laboratories) and immunoblotting using a polyclonal JIP1 antibody (Yasuda et al. 1999|. JNK expression and phosphorylation were examined by immunoblot analysis with antibodies to JNK (PharMingen) and phospho-JNK (Cell Signaling). JNK activity was measured in an in vitro kinase assay using c-Jun as the substrate (Whitmarsh and Davis 2001). Immunoblot analysis was also performed using antibodies purchased from Santa Cruz (antiphosphotyrosine), Upstate Biotechnology (anti-IRS-1 and anti-pSer 307), and Cell Signaling (Akt and anti-pSer 473).

\section{Acknowledgments}

We thank H. Collins for plasma insulin measurements; L. Lesko, J. Reilly, and B. Doran for expert technical assistance; and K. Gemme for administrative assistance. These studies were supported by a grant from the National Institutes of Health. R.J.D. is investigator of the Howard Hughes Medical Institute.

The publication costs of this article were defrayed in part by payment of page charges. This article must therefore be hereby marked "advertisement" in accordance with 18 USC section 1734 solely to indicate this fact.

\section{References}

Aguirre, V., Uchida, T., Yenush, L., Davis, R., and White, M.F. 2000. The c-Jun $\mathrm{NH}(2)$-terminal kinase promotes insulin resistance during association with insulin receptor substrate-1 and phosphorylation of Ser(307). J. Biol. Chem. 275: 9047-9054.

Aguirre, V., Werner, E.D., Giraud, J., Lee, Y.H., Shoelson, S.E., and White, M.F. 2002. Phosphorylation of Ser307 in insulin receptor substrate-1 blocks interactions with the insulin receptor and inhibits insulin action. J. Biol. Chem. 277: 1531-1537.

Bennett, B.L., Satoh, Y., and Lewis, A.J. 2003. JNK: A new therapeutic target for diabetes. Curr. Opin. Pharmacol. 3: 420-425.

Berg, A.H., Combs, T.P., Du, X., Brownlee, M., and Scherer, P.E. 2001. The adipocyte-secreted protein Acrp30 enhances hepatic insulin action. Nat. Med. 7: 947-953.

Boden, G. 1997. Role of fatty acids in the pathogenesis of insulin resistance and NIDDM. Diabetes 46: 3-10.

Bonny, C., Nicod, P., and Waeber, G. 1998. IB1, a JIP-1-related nuclear protein present in insulin-secreting cells. J. Biol. Chem. 273: 18431846.

Dickens, M., Rogers, J.S., Cavanagh, J., Raitano, A., Xia, Z., Halpern, J.R., Greenberg, M.E., Sawyers, C.L., and Davis, R.J. 1997. A cytoplasmic inhibitor of the JNK signal transduction pathway. Science 277: 693696.

Hirosumi, J., Tuncman, G., Chang, L., Gorgun, C.Z., Uysal, K.T., Maeda, K., Karin, M., and Hotamisligil, G.S. 2002. A central role for JNK in obesity and insulin resistance. Nature 420: 333-336.

Im, J.Y., Lee, K.W., Kim, M.H., Lee, S.H., Ha, H.Y., Cho, I.H., Kim, D., Yu, M.S., Kim, J.B., Lee, J.K., et al. 2003. Repression of phospho-JNK and infarct volume in ischemic brain of JIP1-deficient mice. J. Neurosci. Res. 74: 326-332.
Lee, Y.H., Giraud, J., Davis, R.J., and White, M.F. 2003. c-Jun N-terminal kinase (JNK) mediates feedback inhibition of the insulin signaling cascade. J. Biol. Chem. 278: 2896-2902.

Manning, A.M. and Davis, R.J. 2003. Targeting JNK for therapeutic benefit: From junk to gold? Nat. Rev. Drug Discov. 2: 554-565.

Matsuzawa, Y., Funahashi, T., and Nakamura, T. 1999. Molecular mechanism of metabolic syndrome X: Contribution of adipocytokines adipocyte-derived bioactive substances. Ann. NY Acad. Sci. 892: $146-154$

Matsuzawa, Y., Funahashi, T., Kihara, S., and Shimomura, I. 2003. Adiponectin and Metabolic Syndrome. Arterioscler. Thromb. Vasc. Biol. 24: $29-33$.

Mauvais-Jarvis, F., Kulkarni, R.N., and Kahn, C.R. 2002. Knockout models are useful tools to dissect the pathophysiology and genetics of insulin resistance. Clin. Endocrinol. (Oxf.) 57: 1-9.

Michael, M.D., Kulkarni, R.N., Postic, C., Previs, S.F., Shulman, G.I., Magnuson, M.A., and Kahn, C.R. 2000. Loss of insulin signaling in hepatocytes leads to severe insulin resistance and progressive hepatic dysfunction. Mol. Cell 6: 87-97.

Mokdad, A.H., Bowman, B.A., Ford, E.S., Vinicor, F., Marks, J.S., and Koplan, J.P. 2001. The continuing epidemics of obesity and diabetes in the United States. JAMA 286: 1195-1200.

Morrison, D.K. and Davis, R.J. 2003. Regulation of MAP kinase signaling modules by scaffold proteins in mammals. Annu. Rev. Cell Dev. Biol. 19: $91-118$.

Thompson, N.A., Haefliger, J.A., Senn, A., Tawadros, T., Magara, F., Ledermann, B., Nicod, P., and Waeber, G. 2001. Islet-brain1/JNKinteracting protein-1 is required for early embryogenesis in mice. $J$. Biol. Chem. 276: 27745-27748.

Uysal, K.T., Wiesbrock, S.M., Marino, M.W., and Hotamisligil, G.S 1997. Protection from obesity-induced insulin resistance in mice lacking TNF- $\alpha$ function. Nature 389: 610-614.

Waeber, G., Delplanque, J., Bonny, C., Mooser, V., Steinmann, M., Widmann, C., Maillard, A., Miklossy, J., Dina, C., Hani, E.H., et al. 2000 The gene MAPK8IP1, encoding islet-brain-1, is a candidate for type 2 diabetes. Nat. Genet. 24: 291-295.

Whitmarsh, A.J. and Davis, R.J. 2001. Analyzing JNK and p38 mitogenactivated protein kinase activity. Methods Enzymol. 332: 319-336.

Whitmarsh, A.J., Cavanagh, J., Tournier, C., Yasuda, J., and Davis, R.J. 1998. A mammalian scaffold complex that selectively mediates MAP kinase activation. Science 281: 1671-1674.

Whitmarsh, A.J., Kuan, C.Y., Kennedy, N.J., Kelkar, N., Haydar, T.F., Mordes, J.P., Appel, M., Rossini, A.A., Jones, S.N., Flavell, R.A., et al 2001. Requirement of the JIP1 scaffold protein for stress-induced JNK activation. Genes \& Dev. 15: 2421-2432.

Yamauchi, T., Kamon, J., Waki, H., Terauchi, Y., Kubota, N., Hara, K., Mori, Y., Ide, T., Murakami, K., Tsuboyama-Kasaoka, N., et al. 2001 The fat-derived hormone adiponectin reverses insulin resistance associated with both lipoatrophy and obesity. Nat. Med. 7: 941-946.

Yasuda, J., Whitmarsh, A.J., Cavanagh, J., Sharma, M., and Davis, R.J. 1999. The JIP group of mitogen-activated protein kinase scaffold proteins. Mol. Cell Biol. 19: 7245-7254. 


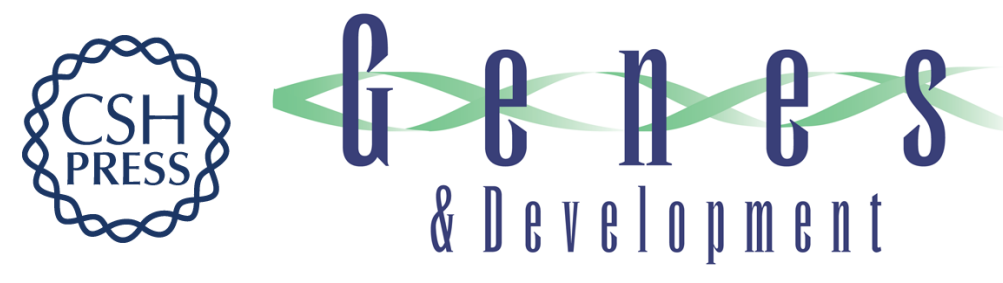

\section{An essential role of the JIP1 scaffold protein for JNK activation in adipose tissue}

Anja Jaeschke, Michael P. Czech and Roger J. Davis

Genes Dev. 2004, 18:

Access the most recent version at doi:10.1101/gad.1216504

References This article cites 24 articles, 10 of which can be accessed free at: http://genesdev.cshlp.org/content/18/16/1976.full.html\#ref-list-1

License

Email Alerting

Receive free email alerts when new articles cite this article - sign up in the box at the top Service right corner of the article or click here.

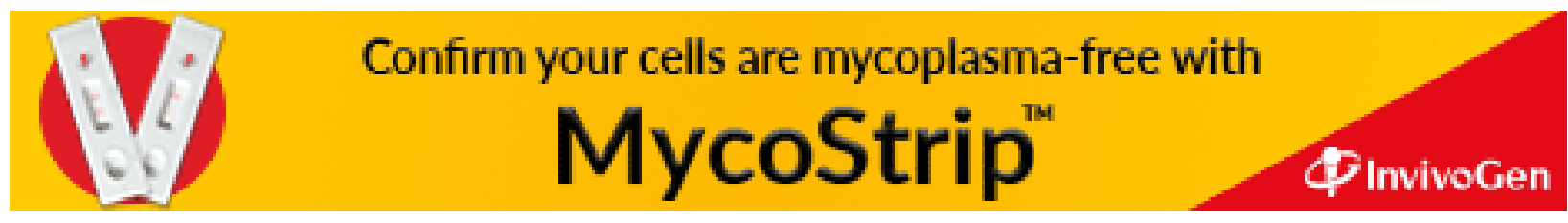

